\title{
Pleiotropic effects of metformin in managing type 2 diabetes and metabolic syndrome: evidences from experimental mouse model.
}

\author{
Christina Gertrude Yap $^{1 *}$, Rakesh Naidu ${ }^{1}$, Kim Dae Jin $^{2}$, Srinivasa Rao Sirasanagandla ${ }^{3}$, Narendra \\ Pamidi $^{1}$ \\ ${ }^{1}$ Jeffrey Cheah School of Medicine and Health Sciences, Monash University Malaysia, Bandar Sunway, 46150 Petaling \\ Jaya, Selangor Darul Ehsan, Malaysia \\ ${ }^{2}$ School of Sciences, Monash University Malaysia, Bandar Sunway, 46150 Petaling Jaya, Selangor Darul Ehsan, \\ Malaysia \\ ${ }^{3}$ Department of Human and Clinical Anatomy, College of Medicine and Heath Sciences, Sultan Qaboos University, \\ Muscat, Oman
}

\begin{abstract}
Background: Metformin is the common first-line medication for treating type 2 diabetes. Besides its anti-hyperglycemic property, various studies have isolatedly shown its effectiveness in reducing body weight and ameliorated components of metabolic syndrome. However, it has not been evidently shown weather metformin is effective as a dual treatment in cases of diet induced obesity and diabetes. We optimized a mouse model for diet induced obesity and diabetes for evaluating dual effectiveness of metformin in treating obesity and diabetes and simultaneously demonstrated histological changes in obese and diabetic kidney and heart tissues and the cellular-protective effects of metformin on these tissues.

Methods: BULB/c mice were fed with normal, high fat or high sucrose diets for $26 \mathrm{w}$. All groups were treated with metformin from $w 16$ to 26 . Blood samples were collected and body weights recorded on $\mathrm{d} 1$ and forth nightly till w 26 when all animals were sacrificed. Hearts and kidneys were dissected and prepared for historical observation. Blood samples were processed accordingly for quantitating blood glucose, ROS and ROS defense (d 1 and d 182).

Results: HFD and HSS feeds successfully created diet induced by obesity and diabetes by $w 15$. Metformin significantly lowered the average body weight of obese group $(p<0.05)$ as well as the average blood glucose levels of the diabetes group $(\mathbf{p}<\mathbf{0 . 0 0 5})$ relative to the respective control groups. Histological studies showed no morphological cellular changes in heart and kidney tissues of obese and diabetic mice relative to respective controls (untreated). Cell shrinkage/'sick cells" were seen in the untreated obese and diabetic mice. ROS levels in the metformin treated mice remained normal relative to the untreated control groups $(\mathbf{p}<\mathbf{0 . 0 5})$.

Conclusions: We have optimized a reliable mouse model for obesity and diabetes. Metformin is effective for controlling diet induced obesity and diabetes. Metformin also showed protection against obesity and hyperglycemia related cell morphological changes.
\end{abstract}

Keywords: Diet induced obesity, Type 2 diabetes, Dual treatment, Metformin, Cellular changes.

\section{Abbreviations}

ROS: Reactive Oxygen Species; HFD: High Fat Diet; HSS:

High Sucrose Solution.

Accepted on September 15, 2018

\section{Introduction}

Socio-economic growth has served as an advent for commercialization of fast foods and fancy beverages while advancement in technologies have contributed to the switch from active to sedentary lifestyles. Unhealthy diet and sedentary lifestyle are among the main risk factors for metabolic diseases including obesity and type 2 diabetes (T2DM) [1].

Obesity continues to be an epidemic worldwide [2] and contributes to the risks for cardio-metabolic diseases [3]. Both 
insulin resistance and impaired insulin secretion develops in obesity and may progress to the development of T2DM [4]. Nevertheless, clinical interventions for diabetes aim to prevent the catastrophic complications and rocketing health budget. An intervention which can simultaneously address obesity and diabetes would be ideal.

Metformin is a first line anti-hyperglycemic agent commonly used to manage patients with type 2 diabetes mellitus (T2DM) [5-7]. Other studies have demonstrated the effectiveness of metformin in lowering body weight $[8,9]$. However, to date no studies have demonstrated the dual effectiveness of metformin for the treatment of diet induced obesity and T2DM in a single model or study.

Although the pathogenesis of obesity is complex, prolonged consumption of high fat diet is capable of inducing obesity $[10,11]$ because excess fats from dietary intake will be stored as triglycerides in adipocytes and subsequently contributes to increase in body weight. Subsequently, in overweight and obesity adipocytes are the sources of various adipokines which play crucial roles in the pathogenesis insulin resistance and progression towards type II diabetes mellitus [12].

On the other hand, consumption of high sugar diet is likely to induce type 2 diabetes mellitus by initiating [13] insulin resistance even in the absence of overweight or obesity. Prolonged consumption of high sugar diet increases the degree of insulin resistance and when pancreatic beta cells fail to compensate in order to maintain blood glucose hemostasis type 2 diabetes develops. Therefore, by optimizing an experimental model to mimic diet-induced obesity and type 2 diabetes in mice we will be able to assess the dual effectiveness of metformin for the treatment of diet induced obesity and T2DM simultaneously.

The objectives of this study are: 1 . To optimize a mouse model for diet induced obesity and T2DM. 2. To demonstrate dual effectiveness of metformin in treating diet induced obesity and T2DM. 3. To observe changes in basic metabolic parameters associated with metabolic disorders such as blood glucose, reactive oxygen species (ROS) and ROS defense. 4. To observe the histological changes in kidneys and cardiac tissues associated with obesity, T2DM and after treatment with metformin.

\section{Materials and Methods}

\section{Animals}

Forty-eight $(\mathrm{N}=48)$, 5-week-old healthy male BALB/c mice, weighing between 20 23 g were purchased from the Animal House in Monash University Malaysia. Mice were housed in individually ventilated poly-carbonate cages (Optimice $^{\circledR}$ caging system) lined with corn cob bedding (BioCOB, Malaysia) and were maintained in a temperature $\left(22^{\circ} \mathrm{C} \pm 1{ }^{\circ} \mathrm{C}\right)$ and humidity $(55 \% \pm 10 \%)$ controlled environment with 12:12 $\mathrm{h}$ light-dark cycle (lights on at $0800 \mathrm{~h}$ and turned off at 2000 h). All cages were maintained on a ventilated cage rack system. The food intake and the general health status of the animals were monitored on daily basis. Food and water were replaced every day, beddings were changed twice a week and cages were autoclaved once a week. Prior to the commencement of the experiment, mice were provided with a standard rodent chow (Glen Forrest, Australia) and water ad libitum for one week to allow them to adapt to the new housing environment. The study was approved by the Monash University Animal Ethics Committee (MUAEC) and animals were handled in compliance with the guide for the care and use of laboratory animals (MARP/2014/109).

\section{Experimental study groups}

After the acclimatization period, mice were randomly divided into four groups of 12 animals $(n=12)$ : normal-diet control (NDC), high-fat diet (HFD) induced obesity, high-sucrose diet (HSD) induced diabetes, and high-fat diet and high-sucrose (HFD+HSD) induced obesity and diabetes. Baseline body weight, non-fasting blood glucose, lipid profile, ROS and ROS defense levels were measured and recorded.

\section{Dietary induction of obesity and diabetes}

Mice were fed ad libitum with HFD, HSD or HFD+HSD accordingly for a period of $15 \mathrm{w}$ to induce the development of obesity or diabetes or obesity+diabetes respectively. HFD group were fed ad libitum with high-fat rodent pellet (45\% kcal fat) $[10,14]$ and water. NC group were given ad libitum supply of standard rodent chow $[14,15]$ and water. HSD group were given free access to standard rodent chow and $40 \%$ sucrosesweetened water. HFD+HSD were provided a combination of high-fat rodent pellet and $40 \%$ sucrose-sweetened water. HFD and standard rodent diet were manufactured by Specialty Feeds, Glen Forest Stock feeders, and Glen Forest, Western Australia.

\section{Confirmation of the induction of obesity and diabetes}

Induction of obesity was confirmed at the end of $15 \mathrm{w}$ (dietary induction period) when the average body weights of animals in the HFD and HFD+HSD groups were significantly higher than the NDC group. Induction of diabetes was confirmed if the non-fasting blood glucose level was greater than $11.0 \mathrm{mmol} / \mathrm{L}$ in any experimental groups.

\section{Redistribution of mice into metformin treated and non-treated groups}

Obese and diabetic mice in each dietary group were randomly subdivided into control $(n=6)$ and treatment groups $(n=6)$ : Normal-diet control (NC) versus Normal-diet treated with metformin $(\mathrm{NC}+\mathrm{M})$; Obese $(\mathrm{O})$ versus obese treated with metformin $(\mathrm{O}+\mathrm{M})$; diabetes $(\mathrm{D})$ versus diabetes treated with metformin $(\mathrm{D}+\mathrm{M})$; obese and diabetes (OD) versus obesity and diabetes treated with metformin $(\mathrm{OD}+\mathrm{M})$. Mice in both control and treatment groups were continuously fed with the previously designated diet until the end of the experimental period (w 26). 

mouse model

\section{Metformin administration}

Metformin (CCM Pharmaceutical, Malaysia) treatment was administered orally to the obese and diabetic mice (groups NC $+\mathrm{M}, \mathrm{O}+\mathrm{M}, \mathrm{D}+\mathrm{M}$ and $\mathrm{OD}+\mathrm{M})$ for a period of $10 \mathrm{w}$ (w 16-26). The metformin dose was $250 \mathrm{mg} / \mathrm{kg}$ body weight [16], once daily. Metformin treatment was administered using an oral gavage needle.

\section{Periodic body weight measurement and plasma biochemistry analysis}

During the $25 \mathrm{w}$ experimental period, the body weight $(\mathrm{g})$ of the mice were measured at an interval of $3 \mathrm{w}$ while the plasma parameters including the lipid profile and blood glucose were measured every $5 \mathrm{w}$ from the start of the experiment. Mice were weighed individually on a weighing boat using a precision weighing balance (Mettler-Toledo, Switzerland). Approximately $1 \mathrm{ml}$ of blood was collected from the retroorbital plexus of the mice (nonfasting state) using a heparinized microhematocrit capillary tube (Vitrex, Denmark). The blood samples were then centrifuged at $1500 \mathrm{X} g$ for 10 min (Beckman Coulter) to separate the plasma from the whole blood. Plasma was transferred into labeled eppendorf tubes using a micropipette (Eppendorf Research) and was stored at $-20^{\circ} \mathrm{C}$ until further analysis was performed. The plasma levels of total cholesterol, triglycerides, LDL-c, HDL-c and blood glucose were assessed using cobas ${ }^{\circledR}-\mathrm{c} 111$ analyzer (Roche Diagnostics).

\section{Blood sampling}

Blood was collected from the retro-orbital plexus. Mice were first anaesthetized by placing them into a confined jar lined with cotton wool dampened with diethyl ether $(\sim 2 \mathrm{ml})$, for approximately $5 \mathrm{~s}$. Once unconscious, it was removed immediately from the jar and gently but firmly held by the loose skin behind its neck. In the later manner the eyelids will be automatically pulled back to expose the eye. The tip of the heparinized micro-hematocrit capillary tube (Vitrex, Denmark) was placed on the medial canthus of the eye at 21 an angle of 45 degree to the side of the head. With a gentle thrust and a turning motion, the micro hematocrit tube was gently inserted into the orbital plexus. When blood began to flow, the tube was pulled back a little to allow the blood to flow along the tube by the capillary action. Approximately $1 \mathrm{~mL}$ of blood was collected into the labelled Eppendorf tubes. After the blood sampling procedure, the eye was wiped clean with a sterile saline-dampened cotton wool and another clean cotton wool was pressed gently against the puncture site of the eye to stop further bleeding. The mice were then transited into a recovery cage until they recovered fully from the effects of anesthesia. During the recovery phase, their respiratory rate and the movement were carefully monitored. The mice were transferred back into their cages once fully recovered.

\section{Histological examination}

All animals were humanely sacrificed using $\mathrm{CO}_{2}$ asphyxiation at the end of $w 25$. Kidneys and hearts were isolated by dissection and immediately placed into labelled specimen jars containing $10 \%$ formalin $(200 \mathrm{ml}$ formaldehyde; Hamburg Germany $+1800 \mathrm{ml}$ distilled water). All specimens were taken through a tissue preparation process [16] and stained with Harris Haematoxylin and Eosin (H\&E) [17] for light microscopy histology.

\section{Statistical analysis}

Data are presented as mean \pm standard error mean (S.E.M.). Statistical analysis was performed using the Sigma Plot 11.2 software (San Jose, CA, USA). Data for each experimental group were compared and tested against the respective control groups for significant changes. To confirm the onset of obesity and diabetes we compared the weight and plasma biochemistry parameters of HFD, HSS and HFD+HSS groups against the normal diet group (NC). For the evaluation of dual effectiveness of metformin treatment for obesity and diabetes we compared plasma biochemistry parameters of each treatment group (NM; OM; DM; ODM) against the respective control groups (NC; O; D; OD). All tests were performed using the one-way ANOVA followed by Bonferroni's multiple comparison post-hoc-test. Differences were considered statistically significant when $\mathrm{p}$ value $<0.05$.

\section{Results}

\section{Changes in body weight during 15 w dietary induction period}

HFD (high fat diet: 45\% kcal fat) (Open source diets, Australia) or a combination of both HFD+HSD (high sucrose diet; $40 \%$ sucrose solution; w/v; equivalent to $160 \% \mathrm{kcal}$ ) were essential in significantly $(\mathrm{p}<0.005)$ inducing obesity in comparison to normal diet (11\% kcal fat) (Open source diets, Australia) (Figure 1A). Initial mean baseline body weight at the start of this study for all animals was $20.85 \pm 0.13 \mathrm{~g}$. There was no significant difference in body weight between all study groups $(p>0.005)$ at the start of the study. Body weight measurements were recorded once every $3 \mathrm{w}$. Animals in groups HFD and HFD+HSD began to show significant increase $(p<0.05)$ in mean body weight at the end of $w 3$ with reference to the ND group (Figure 1A). Mean body weights of HFD and HFD+HSD groups continued to increase throughout the $15 \mathrm{w}$. At the end of $15 \mathrm{w}$ mean body weight of HFD (31.68 $\pm 0.39 \mathrm{~g})$ and HFD+HSD groups $(32.33 \pm 0.27 \mathrm{~g})$ was $\approx 17$ and $20 \%$ higher respectively with reference to ND group $(27.08 \pm$ $0.4 \mathrm{~g})$. Significant increase $(\mathrm{p}<0.05)$ of mean body weight was observed in HFD and HFD+HSD groups at the end of the $15 \mathrm{w}$ dietary induction period. No significant increase in body weight was observed in the HSD group. Therefore, obesity has been induced by dietary intake in animals of groups HFD and HFD+HSD. 


\section{Changes in non-fasting blood glucose levels during 15 $w$ dietary induction period}

Initial mean baseline non-fasting blood glucose (N-FBG) at the start of this study for all animals were $5.15 \pm 0.0096 \mathrm{mmol} / \mathrm{L}$ There was no significant difference in mean N-FBG between all study groups $(p>0.05)$. N-FBG levels were recorded once every $5 \mathrm{w}$. Animals in groups HFD, HSD and HFD+HSD began to show significant increase $(p<0.05)$ in mean N-FBG at the end of $\mathrm{w} 5$ with reference to the ND group (Figure 1B). Mean N-FBG of HFD, HSD and HFD+HSD groups continued to increase throughout the $15 \mathrm{w}$. At the end of $15 \mathrm{w}$ mean NFBG of HFD $(8.138 \pm 0.013 \mathrm{mmol} / \mathrm{L}), \mathrm{HSD}(12.15 \pm 0.018$ $\mathrm{mmol} / \mathrm{L})$ and HFD+HSD $(12.64 \pm 0.01 \mathrm{mmol} / \mathrm{L})$ groups were significantly higher $(\mathrm{p}<0.05)$ with reference to ND group $(5.65$ $\pm 0.047)$. Significant increase $(p<0.05)$ in mean $N-F B G$ was observed in HFD, HSD and HFD+HSD groups at the end of the $15 \mathrm{w}$ dietary induction period. The normal reference limits for $\mathrm{N}-\mathrm{FBG}$ is $4.0-7.8 \mathrm{mmol} / \mathrm{L}$. N-FBG between $7.9-11.1$ $\mathrm{mmol} / \mathrm{L}$ are defined as pre-diabetes because these values are higher than the normal limits but not high enough to be classified as diabetes. Type 2 diabetes is when N-FBG is $>11.1$ mmol/L (https://doi.org/10.21769/BioProtoc.159). At the end of the $15 \mathrm{w}$ dietary induction period N-FBG of animals in HSD $(12.15 \pm 0.018 \mathrm{mmol} / \mathrm{L})$ and HSD+HFD (12.64 \pm 0.01 $\mathrm{mmol} / \mathrm{L})$ groups exceeded $11.0 \mathrm{mmol} / \mathrm{L}$ and therefore have developed type 2 diabetes. N-FBG level in animals of HFD group $(8.14 \pm 0.044 \mathrm{mmol} / \mathrm{L})$ was significantly higher $(\mathrm{p}<0.05)$ with reference to ND group $(5.65 \pm 0.047 \mathrm{mmol} / \mathrm{L})$. Since NFBS for HFD group is $>7.9 \mathrm{mmol} / \mathrm{L}$ but $<11.1 \mathrm{mmol} / \mathrm{L}$, animals in HFD group has developed pre-diabetes.

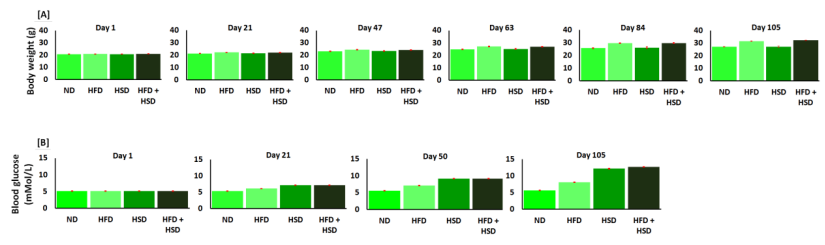

Figure 1. Development of diet induced obesity and diabetes. Diet induced increment in body weight ( $g$ ) following consumption of normal diet (ND), high fat diet (HFD), high sucrose diet (HSD) or combination of HFD and HSD (HFD $+H S D)$ showed mean body weight increment for animals fed with HFD and HFD+HSD were significantly higher at $d 105$ relative to $d 1$ ( $p<0.05)$ (A); Diet induced increment in blood glucose levels ( $\mathrm{mmol} / \mathrm{L})$ following consumption of normal diet (ND), high fat diet (HFD), high sucrose diet (HSD) or combination of HFD and HSD (HFD+HSD) showed mean blood glucose increment for animals fed with HFD+HSD, HSD and HFD (HFD $+H S D>H S D>H S D)$ were significantly higher at $d$ 105 relative to $d 1(p<0.05)(B)$.

\section{Dual effects of $10 \mathrm{w}$ metformin treatment for diet induced diabetes and obesity}

After the dietary induction period of $15 \mathrm{w}$ all animals were redistributed treatment and control groups as explained in 2.1.5. All animals were continually fed with the previously designated diet and treated with $250 \mathrm{~g} / \mathrm{kg}$ body weight metformin for $10 \mathrm{w}$. Statistically significant reduction $(\mathrm{p}<0.05)$ in blood glucose and body weight was seen at the end of w 10 (Figure 2).

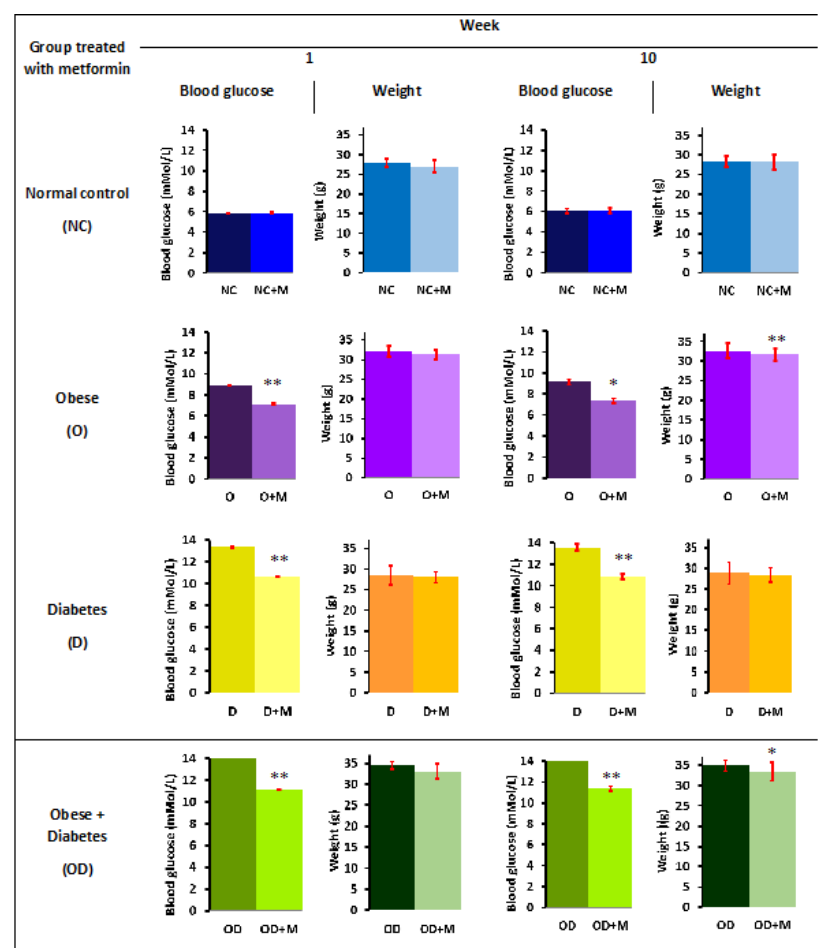

Figure 2. Changes in body weight and blood glucose after treatment with metformin. All data were collected on the last day of $w 1$ and $w$ 10 respectively. Data plotted represents mean $\pm S D$ of respective groups. $\quad{ }^{*} p<0.05, \quad{ }^{* *} p<0.001$. P-values refer to parametric comparison between metformin treated and non-treated groups (using Student's t-test). Metformin treated groups generally showed significantly lower body weight and blood glucose.

\section{Effect of metformin on body weight}

Metformin treated obese as well as diabetic (OD+M) and obese $(\mathrm{O}+\mathrm{M})$ groups showed significant reduction in body weight ( $p=0.003$ and $p=0.001$ respectively) after 10 weeks. Mean body weight of $\mathrm{OD}+\mathrm{M}$ and $\mathrm{O}+\mathrm{M}$ groups were $12 \%$ and $11 \%$ lower at the end of $10 \mathrm{w}$ metformin treatment period respectively, relative to mean body weights of $(\mathrm{OD}+\mathrm{M})$ and $(\mathrm{O}+\mathrm{M})$ groups at the beginning of $\mathrm{w} 1$. Other study groups $(\mathrm{NC}, \mathrm{NC}+\mathrm{M}, \mathrm{D}, \mathrm{D}$ $+\mathrm{M})$ did not show any significant reduction in body weight. Nevertheless, these observations suggest that diet induced obesity can be controlled oral metformin treatment.

\section{Effect of metformin on blood glucose levels}

Statistically significant reduction in blood glucose level was evidently observed in the metformin treated obese as well as diabetic $(\mathrm{OD}+\mathrm{M})$, obesity $(\mathrm{O}+\mathrm{M})$ and diabetic $(\mathrm{D}+\mathrm{M})$ groups relative to their respective controls (OD, O and D groups) at the end of $10 \mathrm{w}$ oral metformin treatment (Figure 2). Mean non-fasting blood glucose for $(\mathrm{O}+\mathrm{M})$ group $(6.25 \pm 0.02$ $\mathrm{mmol} / \mathrm{L})$ was $52 \%$ lower $(\mathrm{p}<0.05)$ compared to the non-treated group $(\mathrm{O})(9.528 \pm 0.04 \mathrm{mmol} / \mathrm{L}) .(\mathrm{OD}+\mathrm{M})$ group $(9.65 \pm 0.02$ $\mathrm{mmol} / \mathrm{L})$ was $62 \%$ lower $(\mathrm{p}<0.05)$ compared to the untreated 
Pleiotropic effects of metformin in managing type 2 diabetes and metabolic syndrome: evidences from experimental mouse model

group (OD) $(15.63 \pm 0.04 \mathrm{mmol} / \mathrm{L}) .(\mathrm{D}+\mathrm{M})$ group $(9.15 \pm 0.01$ $\mathrm{mmol} / \mathrm{L})$ was approximately $59 \%$ lower $(\mathrm{p}<0.05)$ than the nontreated diabetic group (D) $(14.55 \pm 0.04 \mathrm{mmol} / \mathrm{L})$. These observations showed evidence that metformin is effective in preventing elevation of blood glucose level due to high fat (HFD) and high sucrose diets (HSD). $10 \mathrm{w}$ oral metformin treatment evidently showed blood glucose lowering effects in high fat (HFD) and high sucrose (HSD) induced diabetes and obesity.
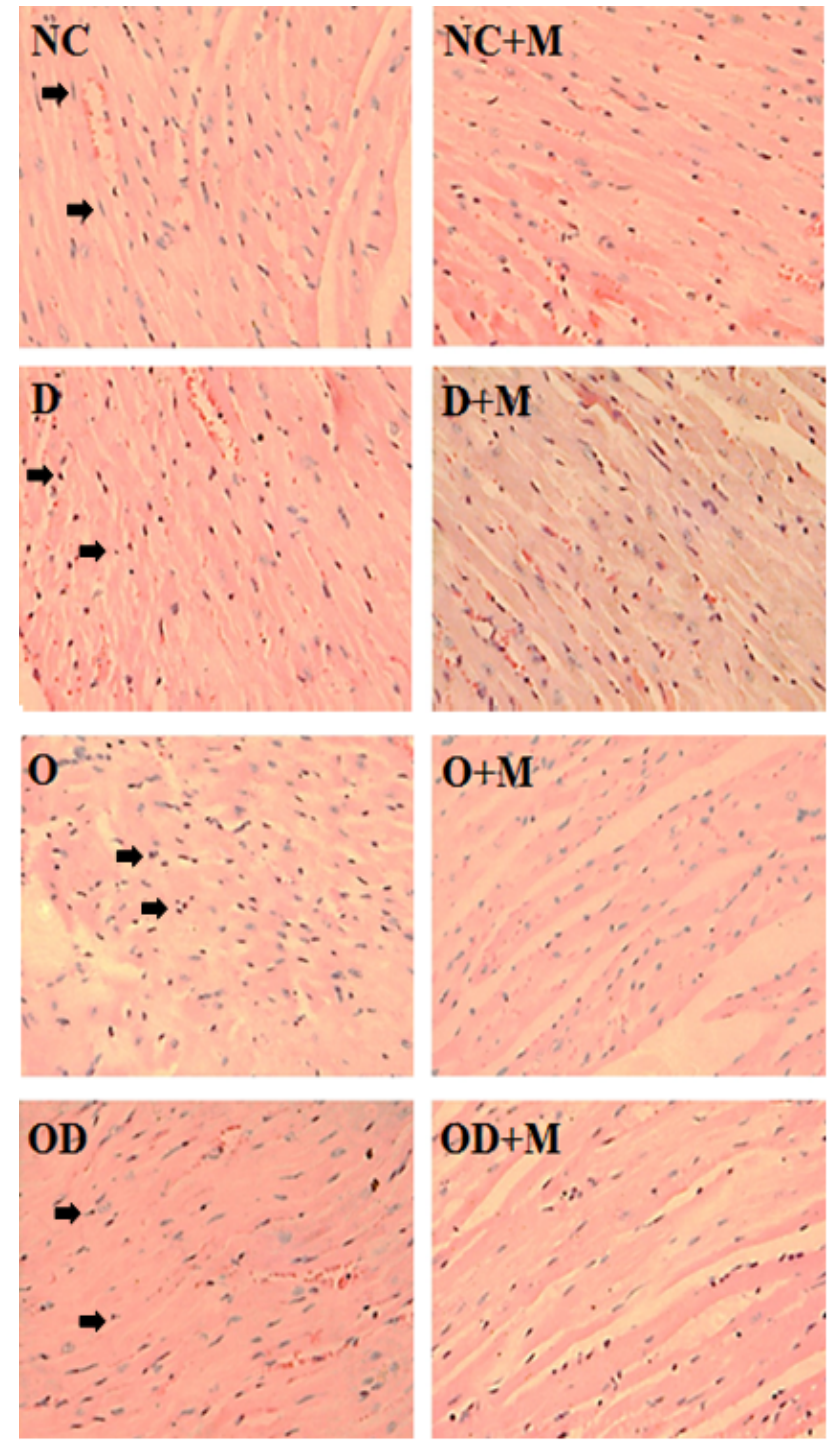

$\Longrightarrow$

Figure 3. Obesity and diabetes induced histological changes in heart tissues. Histology of heart tissue stained with $H \& E$ and captured under light microscope at $40 X$ magnification. NC: Normal Control; $N C+M$ : Normal Control treated with Metformin; D: Diabetes; $D+M$; Diabetes treated with Metformin; O: Obese; $O+M$ : Obese treated with Metformin; OD: Obese and Diabetes; OD+M: Obese and Diabetes treated with Metformin. Arrow marked in NC showing normal cells. Arrows in D, O,OD showing cell shrinkage and small spherical nuclei. NCM, DM, OM and ODM the cells are quite similar to $N C$ with elongated nuclei.

\section{$10 \mathrm{w}$ metformin treatment prevented cellular changes in heart and kidney}

Histological study showed high fat and high sucrose dietinduced diabetes and obesity (D, O, DO) also resulted in morphological cellular changes in heart (Figure 3) and kidney (Figure 4) tissues in comparison to the normal diet (NC) group. Moderate cell shrinkage/"sick cells" and irregular structural boundaries seen in heart (Figure 3) and kidney (Figure 4) tissues from untreated diabetic and obese mice (D, O, DO). On the other hand, $10 \mathrm{w}$ oral metformin treated diabetic and obese mice $((\mathrm{D}+\mathrm{M}),(\mathrm{O}+\mathrm{M}),(\mathrm{OD}+\mathrm{M}))$ showed normal histology in heart (Figure 3) and kidney (Figure 4) tissues similar to the normal diet group (NC).

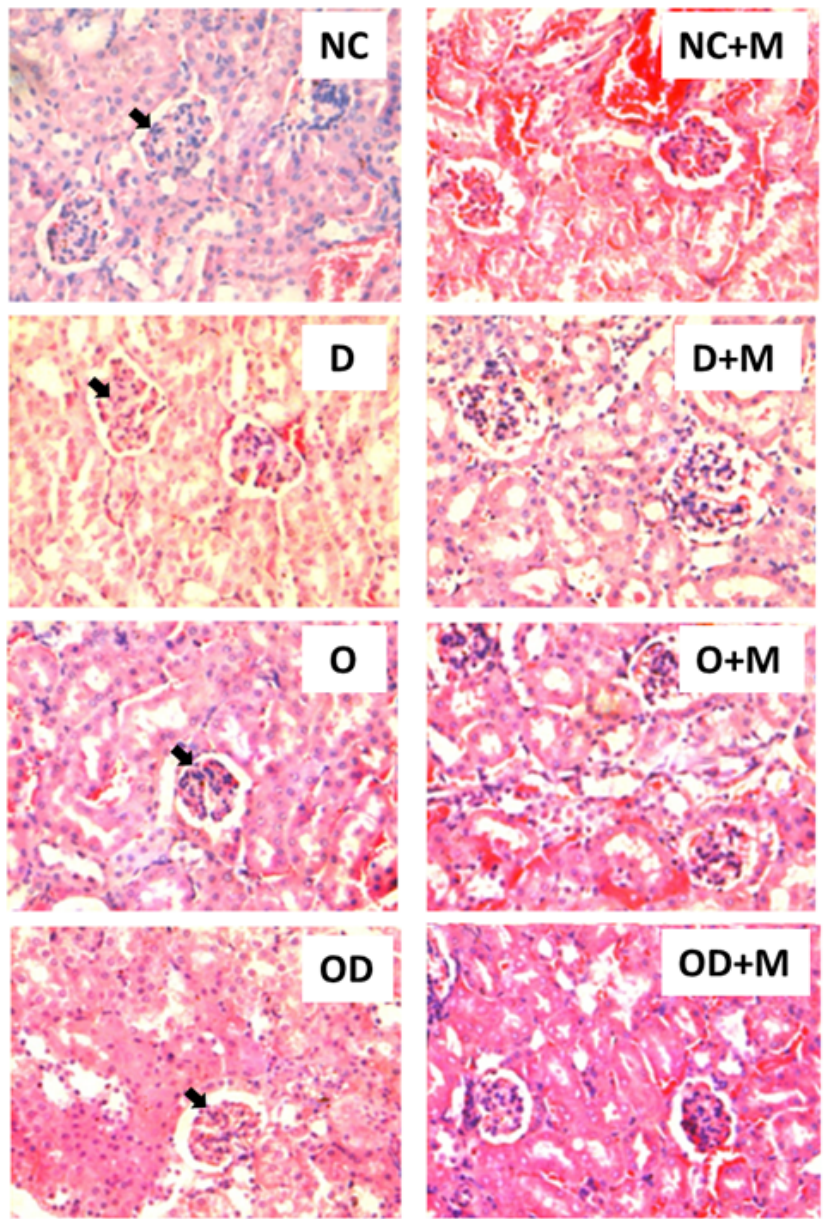

Figure 4. Obesity and diabetes induced histological changes in renal cortex tissue. Histology of renal cortex tissue stained with $H \& E$ and captured under light microscope at $40 X$ magnification. NC: Normal Control; NC+M: Normal Control treated with arrow Marked in NC showing normal cells. Arrows in D, O, OD showing cell shrinkage. NCM, DM, OM and ODM the cells are quite similar to NC.

\section{ROS and ROS defense levels in consumption of HFD}

We observed that HFD effectively induced diabetes and obesity. Since ROS plays a role in the pathogenesis of diabetes and its complications [19] we investigated ROS and ROS defense levels in the animals which were fed with HFD only. No significant difference $(p>0.05)$ in ROS levels in HFD group 
relative to control (ND group) at the start of the start of the study (d 0) and after $182 \mathrm{~d}$ of HFD feeding (d 182), (Figure $5 \mathrm{~A})$. The later observation may suggest that the in situ ROS defense system was effective in maintaining ROS at homeostatic levels $\left(<2.36 \mathrm{mmol} / \mathrm{L} \mathrm{H}_{2} \mathrm{O}_{2}\right.$ equivalents).

On the other hand, ROS defense levels measured in HFD group was not significantly different $(p>0.05)$ from control group at the start of the study (d 0). At d 0, ROS defense levels in both control and HFD groups were within normal reference limits (1.07-1.53 mmol/L Trolox equivalent). However, after $182 \mathrm{~d}$ (d 182) HFD feeding, significant decrease in ROS defense level $(\mathrm{p}<0.05)$ was observed in the HFD group relative to $\mathrm{d} 0$ (Figure $5 \mathrm{~B}$ ). The decrease in ROS defense levels in HFD group at d 182 evidently suggest that the antioxidant capacity of in situ ROS defense system had been challenged. With reference to the later an imbalance of oxidants (ROS) and antioxidants (in situ ROS defense system) has occurred during the $182 \mathrm{~d}$ HFD feeding. Hence this study evidently showed that HFD fed to oxidative stress due to increasing levels of ROS occurred during the $182 \mathrm{~d}$ HFD feeding. There were no significant difference in ROS defense levels in the control group at $\mathrm{d} 182$ relative to $\mathrm{d} 0(\mathrm{p}>0.05)$.

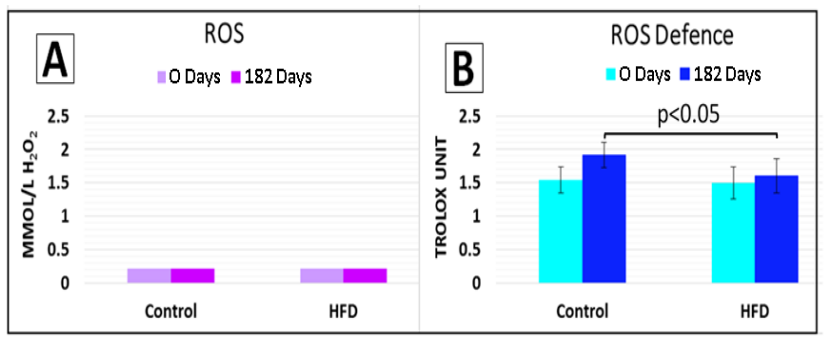

Figure 5. ROS and ROS defense levels in diet induced obesity and diabetes. ROS (A) and ROS defense (B) levels quantitated before (0 d) and after 182 of HFD consumption. There was no increase in ROS after HFD consumption for 30 d relative to the control group. ROS defense levels increased in both control and HFD groups but the level in HFD group was significantly lower than control group $(p>0.05)$. This observation suggests that high amounts of ROS was generated due to HFD metabolism relative to normal diet (Control) and the in-vivo ROS defense system shows depletion due to its excessive function to maintain ROS homeostasis $(A)$.

\section{Effects of HFD and HSD feeding on plasma lipid profile and subsequent metformin treatment}

Total cholesterol: Average baseline for total cholesterol (TC) for all study groups were $4.1 \mathrm{mmol} / \mathrm{L}$ and initially there were no significant difference $(\mathrm{p}>0.05)$ between all study groups. Significant increase $(p<0.05)$ in TC level was seen in HFD and HFD+HSD groups on the $7^{\text {th }}$ week and HSD group after $10 \mathrm{w}$ of specified diet feeding with reference to ND (control) group. At the end of $15 \mathrm{w}$ mice fed with HFD+HSD $(\mathrm{TC}=5.58 \pm 0.03$ $\mathrm{mmol} / \mathrm{L})$, HFD alone (TC=5.45 $\pm 0.02 \mathrm{mmol} / \mathrm{L})$ and HSD alone $(4.77 \pm 0.02 \mathrm{mmol} / \mathrm{L})$ were $22 \%, 19 \%$ and $4 \%$ higher respectively compared to the ND group $(\mathrm{TC}=4.57 \pm 0.02$ $\mathrm{mmol} / \mathrm{L}$ ) (Figure 6).

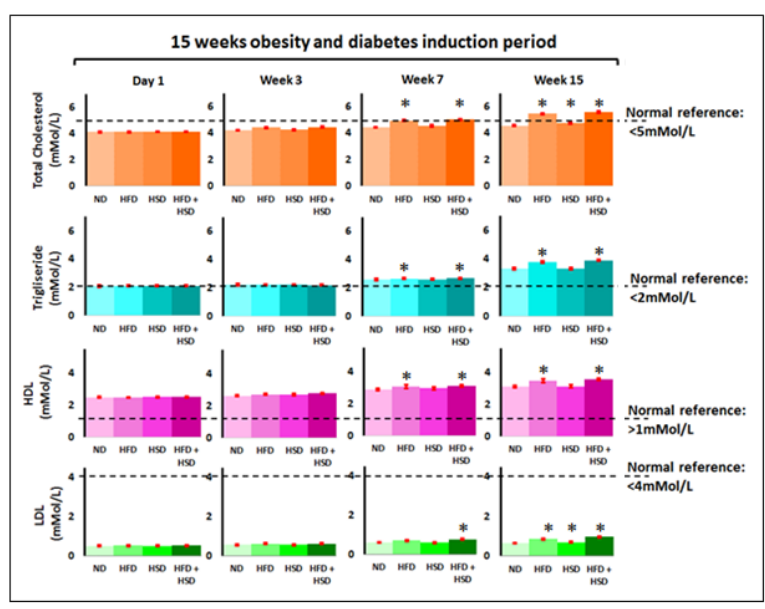

Figure 6. Changes in lipid profile during the development of type 2 diabetes and obesity. Significant increase in total cholesterol, and $L D L$ was observed with the HFD, HSD and HFD+HSD consumption. Significant increase in triglycerides and $H D L$ was observed only with the HFD and HFD $+H S D$ feeding.

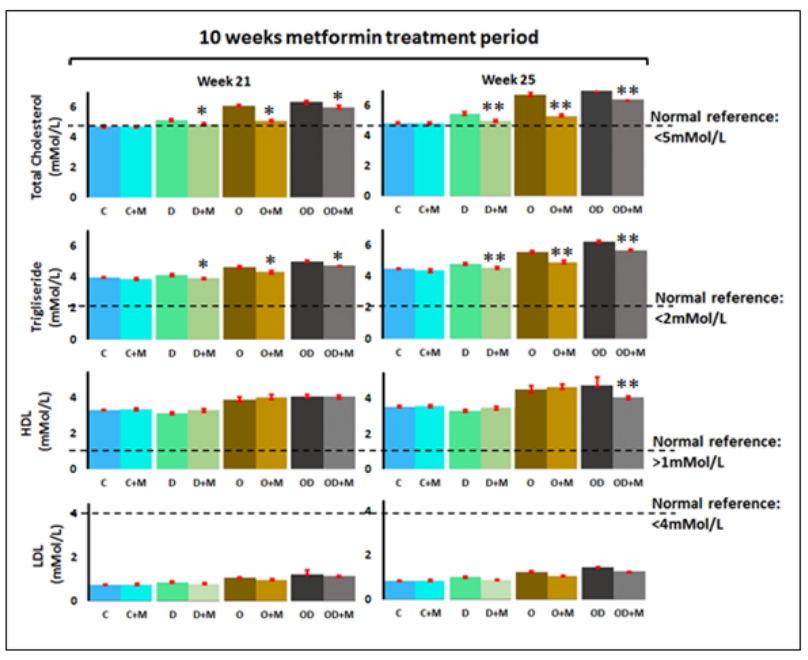

Figure 7. $10 \mathrm{w}$ metformin treatment on diet induced dyslipidemia in mice. Metformin treated groups showed significantly lowered total cholesterol and triglyceride in diabetic $(D+M)$, obese $(O+M)$ and diabetic + obese $(O D+M)$ mice relative to the respective controls $(D$, $O$, OD).Data plotted represents mean $\pm S D$ of respective groups. ${ }^{*} p>0.05, \quad{ }^{* *} p<0.05, \quad{ }^{* * *} p>0.001 . \quad P$-values refer to parametric comparison between metformin treated and non-treated groups (using Student's t-test).

Triglycerides: Average baseline triglycerides (TG) level was $2.1 \mathrm{mmol} / \mathrm{L}$ in all study groups with no significant difference between study groups (Figure 6). After $7 \mathrm{w}$ of feeding, significantly $(\mathrm{p}<0.05)$ higher TG levels were seen in HFD and HFD+HSD groups with reference to the ND (normal diet/ control) group. At the end of $15 \mathrm{w}$ feeding period, mean TG for HFD+HSD $(3.87 \pm 0.017)$ and HFD $(3.75 \pm 0.02 \mathrm{mmol} / \mathrm{L})$ group had increased by $17 \%$ and $13 \%$ respectively relative to ND group (3.31 $\pm 0.02 \mathrm{mmol} / \mathrm{L})$ (Figure 6). Mean TG level for 

mouse model

HSD group did not differ significantly $(\mathrm{p}>0.05)$ from the ND group at the end of $15 \mathrm{w}$ feeding period (Figure 6).

HDL-cholesterol: Initial mean HDL-cholesterol baseline levels in all study groups were $2.5 \mathrm{mmol} / \mathrm{L}$. Significant increase in HDL-cholesterol levels $(p<0.05)$ were seen in HFD + HSD and HFD with reference to the ND group after $7 \mathrm{w}$ of feeding. At the end of $15 \mathrm{w}$ feeding with respective diet type, HDL- cholesterol levels increased by $14 \%$ in HFD+HSD (3.55 $\pm 0.02 \mathrm{mmo} / \mathrm{L}), 12 \%$ in HFD $(3.48 \pm 0.04 \mathrm{mmol} / \mathrm{L})$ groups respectively with reference to $\mathrm{ND}(3.101 \pm 0.02 \mathrm{mmol} / \mathrm{L})$ group. HSD group $(3.11 \pm 0.09 \mathrm{mmol} / \mathrm{L})$ did not show significant increase in HDL cholesterol level $(p>0.05)$ in comparison to the ND group at the end of 15 week feeding period (Figure 6).

LDL-cholesterol: Similarly, there were no significant differences in the baseline levels for LDL-cholesterol in all groups and the mean initial level was $0.5 \mathrm{mmol} / \mathrm{L}$. After $7 \mathrm{w}$ of feeding the HFD+HSD group began to show significant increase in LDL cholesterol with reference to the ND group. At the end of $15 \mathrm{w}$ feeding period the HFD+HSD $(0.97 \pm 0.01$ $\mathrm{mmol} / \mathrm{L}), \operatorname{HFD}(0.86 \pm 0.01 \mathrm{mmol} / \mathrm{L})$ and $\operatorname{HSD}(0.70 \pm 0.01$ $\mathrm{mmol} /$ ) groups showed significantly increased means $(\mathrm{p}<0.05)$ for LDL-cholesterol levels by $47 \%, 31 \%$ and $7 \%$ respectively in comparison to the ND $(0.66 \pm 0.01 \mathrm{mmol} / \mathrm{L})$ group (Figure $6)$.

\section{Effects of 10 w metformin treatment on diet induced dyslipidemia in mice}

Findings from this study clearly showed that $15 \mathrm{w}$ of feeding with HFD+HSD (OD group; obese + diabetes), HFD alone (O group; obese) or HSD alone (D group; diabetes) induced dyslipidemia in mice. However, parallel experimental groups which were fed with their respective designated diet type and at the same time treated with metformin: $\mathrm{OD}+\mathrm{M}, \mathrm{O}+\mathrm{M}$ and $\mathrm{D}$ $+\mathrm{M}$. All treated groups showed much milder elevations in lipid profile indices (Figure 7 and Table 1). We observed that $10 \mathrm{w}$ oral metformin treatment lowered diet-induced body weight by $3-4 \%(\mathrm{p}<0.05)$, blood glucose by $\approx 20 \%(\mathrm{p}<0.05)$ and controlled dyslipidemia. Our observations suggest that continuous treatment with metformin will prevent diet induced risks of developing metabolic syndrome disorders and complications.

Table 1. Effects of $10 \mathrm{w}$ oral metformin treatment on metabolic indices. Metabolic indices quantitated in plasma to compare metformin treated and non-treated groups for various diet-induced obesity and/or diabetes. P-values refer to parametric comparison between metformin treated and nontreated groups (using Student's t-test). Metformin treated groups generally showed significantly lower body weight and metabolic indices relative to the non-treated groups. Visualization of the significant differences in metabolic indices between metformin treated and non-treated groups are demonstrated in Figures 2 and 5.

\begin{tabular}{|c|c|c|c|c|c|c|}
\hline \multirow[t]{2}{*}{ Diet type } & \multirow{2}{*}{$\begin{array}{l}\text { Induced metabolic } \\
\text { status }\end{array}$} & \multirow[t]{2}{*}{ Metabolic indices } & \multicolumn{2}{|c|}{ Metformin ( $2 \mathrm{mg} / 10 \mathrm{~g}$ body weight) } & \multirow[t]{2}{*}{$P$ value } & \multirow{2}{*}{$\begin{array}{l}\% \text { reduction after metformin } \\
\text { treatment }\end{array}$} \\
\hline & & & Non-treated & Treated & & \\
\hline \multirow[t]{6}{*}{ ND (Control) } & No+non-diabetic & Body weight (g) & $27.29 \pm 1.45$ & $28.26 \pm 1.95$ & $>0.05$ & No significant reduction \\
\hline & & Blood glucose (mmol/L) & $6.05 \pm 4.27$ & $6.06 \pm 4.25$ & $>0.05$ & No significant reduction \\
\hline & & T-chol (m mol/L) & $4.83 \pm 4.063$ & $4.81 \pm 4.58$ & $>0.05$ & No significant reduction \\
\hline & & $\mathrm{TG}(\mathrm{m} \mathrm{mol} / \mathrm{L})$ & $4.46 \pm 4.03$ & $4.36 \pm 4.09$ & $>0.05$ & No significant reduction \\
\hline & & HDL-chol (mmol/L) & $3.57 \pm 4.06$ & $3.60 \pm 4.08$ & $>0.05$ & No significant reduction \\
\hline & & LDL-chol (mmol/L) & $0.86 \pm 0.02$ & $0.86 \pm 4.04$ & $>0.05$ & No significant reduction \\
\hline \multirow[t]{6}{*}{ HFD+HSD } & Obese+diabetes & Body weight (g) & $34.9 \pm 1.33$ & $33.43 \pm 2.21$ & $<0.005$ & $4.3 \% \downarrow$ \\
\hline & & Blood glucose (mmol/L) & $14.33 \pm 0.239$ & $11.3 \pm 54.3$ & $<0.001$ & $20.8 \% \downarrow$ \\
\hline & & T-chol (mmol/L) & $6.97 \pm 4.11$ & $6.40 \pm 4.10$ & $<0.001$ & $8.2 \%$ \\
\hline & & $\mathrm{TG}(\mathrm{mmol} / \mathrm{L})$ & $6.20 \pm 4.07$ & $5.67 \pm 4.06$ & $<0.001$ & $8.5 \%$ \\
\hline & & HDL-chol (mmol/L) & $4.76 \pm 4.05$ & $4.67 \pm 4.11$ & $>0.05$ & No significant reduction \\
\hline & & LDL-chol ( mmol/L) & $1.46 \pm 4.03$ & $1.28 \pm 4.03$ & $<0.001$ & $12.3 \% \downarrow$ \\
\hline \multirow[t]{5}{*}{ RFD } & Obese & Body weight (g) & $32.5 \pm 1.91$ & $31.66 \pm 1.56$ & $<0.001$ & $2.7 \% \downarrow$ \\
\hline & & Blood glucose (mmol/lL) & $9.13 \pm 4.25$ & $7.35 \pm 4.23$ & $<0.001$ & $19.5 \% \downarrow$ \\
\hline & & T-chol (mmol/l) & $6.69 \pm 4.08$ & $5.30 \pm 4.05$ & $<0.005$ & $20.8 \% \downarrow$ \\
\hline & & $\mathrm{TG}(\mathrm{mmol} / \mathrm{l})$ & $5.54 \pm 4.03$ & $4.91 \pm 4.04$ & $<0.001$ & $11.4 \% \downarrow$ \\
\hline & & HDL-chol (mmol/L) & $4.56 \pm 0.21$ & $4.67 \pm 4.13$ & $>0.05$ & No significant reduction \\
\hline
\end{tabular}




\begin{tabular}{llllll} 
& LDL-chol (mmo//) & $1.26 \pm 0.05$ & $1.07 \pm 4.02$ & $<0.001$ & $15.1 \% \downarrow$ \\
\hline HSD Diabetes & Body weight (g) & $28.87 \pm 2.65$ & $28.39 \pm 1.75$ & $>0.05$ & No significant reduction \\
\hline & Blood glucose (mmol/L) & $13.5 \pm 54.23$ & $10.8 \pm 54.23$ & $<0.001$ & $19.9 \% \downarrow$ \\
\hline T-chol (mmol/L) & $5.45 \pm 4.11$ & $4.96 \pm 4.07$ & $<0.001$ & $9.0 \% \downarrow$ \\
\hline TG (mmol/L) & $4.8 \pm 4.09$ & $4.52 \pm 4.08$ & $<0.001$ & $5.9 \% \downarrow$ \\
\hline HDL-chol (mmol/L) & $3.33 \pm 0.05$ & $3.49 \pm 4.09$ & $<0.05$ & $4.6 \% \downarrow$ \\
\hline LDL-chol (mmol/l) & $1.02 \pm 4.04$ & $0.89 \pm 4.02$ & $<0.001$ & $12.7 \% \downarrow$ \\
\hline
\end{tabular}

\section{Discussion}

Metformin is the common first-line treatment for type 2 diabetes [20] with negligible side effects [21]. Besides its glucose-lowering effect, it has also been shown to assist modest weight reduction and improve plasma lipid levels $[22,23]$. The revolution of intelligent technology has positively impacted on the prevalence of "diabesity", a term describing the coexistence of obesity and diabetes, has been increasing over the past few decades [24,25]. Treating and managing both obesity and diabetes at the same time can be a challenge because some of the hypoglycemic drugs such as sulphonylureas and insulin are frequently associated with weight gain [24]. GLP-1 analogues have been shown to be able to treat both obesity and diabetes but are not cost effective to a proportion of the society [25]. Metformin is relatively affordable and has a good safety profile [23] but has not been evidently proven to effectively address both obesity and diabetes simultaneously.

The liver plays a crucial role in dietary lipid (fat) handling ensuring regulation of storage, assortment, outflow and synthesis of lipids in-situ [26]. The regulation of all lipid anabolic and catabolic processes are very complex and an imbalance between the amount on lipids intake and the rates of lipid metabolism homeostasis may lead to metabolic disorders including obesity, dyslipidemia, insulin resistance, and cardiovascular diseases. An ideal healthy diet should contain $20-35 \%$ fat, $10-35 \%$ protein, and $45-65 \%$ carbohydrate [27]. The current study evidently demonstrated that continuous consumption of $45 \% \mathrm{kcal}$ diet (HFD) for $15 \mathrm{~d}$ significantly increased body weight in mice, while the increment in body weight was enhanced with a combination diet containing $45 \%$ kcal (HFD) and 160\% kcal (HSD; 40\% sucrose solution; $1 \mathrm{~g}$ sucrose $=4 \mathrm{kcal})$. However, consistent with other studies [28] HSD alone did not result in significant weight gain but aggressive behavior among group mates was observed as scares, bleeding scratches and bites. Currently scarce scientific evidence are available to explain the correlation between HSD and the development of aggressive behavior. Also, in the current study did not quantitate total caloric intake of the mice therefore we are not able to describe whether the lack of body weight gain seen with the mice fed HSD was due to a reduction in the total caloric intake. At this point it is surface to note that the mortality rate for animals in the HFD group is approximately $8 \%$ therefore, sufficient number of animals should be planned at the start of this study.

This current study compared four varieties of diets: HFD, HSD, HFD+HSD, ND (control) significantly $(\mathrm{p}<0.05)$ demonstrated elevated blood glucose in the HFD, HSD and $\mathrm{HFD}+\mathrm{HSD}$ at the end of $15 \mathrm{w}$ (Figure 1B). HFD induced impaired glucose tolerance (IGT) $(\mathrm{N}-\mathrm{FBG}=7.9-11.1 \mathrm{mmol} / \mathrm{L})$, which is a stage in the spectrum of hyperglycemia the natural history of diabetes preceding "true" clinical diabetes $(\mathrm{N}$ $\mathrm{FBG}>11.1 \mathrm{mmol} / \mathrm{L})$. HSD induced diabetes, while combination of HFD+HSD induced diabetes with potentiated hyperglycemic effect. Nevertheless, this mice model protocol is optimal for use in studies which require experimental induction of obesity and diabetes using HFD (45\% kcal fat), HSD (40\% sucrose solution; w/v; equivalent to $160 \% \mathrm{kcal}$ ) and a combination of HFD+HSD.

$10 \mathrm{w}$ (w 16-25) oral metformin treatment evidently demonstrated 4.3\% $(\mathrm{p}<0.005)$ and $2.7 \%(\mathrm{p}<0.001)$ lower body weight in HFD and HFD+HSD groups comparison to the respective non-treated groups (Figure 2). Metformin is an insulin sensitizer that lowers blood glucose without increasing the plasma concentration of insulin. Thus, metformin does not cause hypoglycemia or weight gain associated with high plasma concentration of insulin. Instead, metformin therapy is frequently associated with weight loss, which is a welcoming side-effect for diabetic patients who are obese [29,30]. The results in Figure 2 suggest that metformin is a competent antiobesity agent. Nevertheless, future studies are needed to assess its long term anti-obesity effect. The mechanism of action of metformin in weight reduction is currently not fully understood. Some studies stated that metformin induced weight reduction by reducing the food consumption [22]. Other studies suggested that metformin reduces appetite by increasing the plasma level of glucagon-like peptide 1 (GLP-1) GLP-1 is an incretin released from the intestinal L cells upon increase in the postprandial blood glucose [31]. GLP-1 is known to promote satiety and inhibit food intake [31]. Thus, the lack of weight gain observed in the mice treated with metformin could be due to reduced food intake caused by a loss of appetite. However, as the precise food intake of the mice was not measured, we are unable to determine whether the lack of body weight gain was a result of a reduction in the food intake. Matsui et al. [32] documented that a single oral administration of $300 \mathrm{mg} / \mathrm{kg}$ metformin markedly reduced the food consumption in mice for $2 \mathrm{~h}$. The latter study also noted a 


\section{Pleiotropic effects of metformin in managing type 2 diabetes and metabolic syndrome: evidences from experimental mouse model}

concurrent increase in the plasma level of GLP-1 alluding that metformin facilitates weight reduction by reducing the appetite [32]. Various other rodent studies, long-term feeding of high fat or high-sucrose diet results in metabolic abnormalities such as obesity, hyperglycemia, dyslipidemia and insulin resistance [33-37]. Some studies suggest that metformin aids weight loss by improving insulin resistance. It is thought an improvement in the insulin sensitivity reduces the frequency of postprandial hypoglycemia and consequently reduces the hunger after a meal and unnecessary food consumption [38,39]. Metformin is also known to decrease glucose absorption in the gut. Thus less glucose will be available to be converted into fat in the liver and stored in the adipose tissue [40].

Metformin is a well-established oral anti-hyperglycemic agent used for the treatment of type-2 diabetes [22]. Our study is consistent with other studies demonstrating that metformin therapy significantly reduced blood glucose level of the mice fed HFD and HSD. Metformin therapy restored normoglycemia in mice fed HSD+metformin. However, blood glucose level of the mice in ODM and DM group was still higher than that of the mice in ND group presuming that longer period of treatment is required to restore normal blood glucose level in these groups. Metformin lowers blood glucose level by primarily suppressing glucose production in the liver and secondarily by improving insulin sensitivity of the peripheral tissues [41].

Metformin treatment is very efficient in preventing the histological changes of high fat diet induced organs [42]. In the present study, high sucrose, high fat and combination of both diets fed rats resulted in moderate histological changes in the cardiac muscle and kidney and metformin markedly prevented the cell damage in treated groups. Photomicrographs of the representative sections stained with $\mathrm{H} \& \mathrm{E}$ of the cardiac muscle and kidney of NC (mice fed with normal diet) and $\mathrm{NC}+\mathrm{M}$ (mice fed normal diet and treated with metformin) showed visible population of clear cortex with renal corpuscles, renal tubules (kidney), nuclei and normal architecture of cardiac muscle fibers (branching). Diabetic (HSD) and obese (HFD) and combination of both the mice showed a moderate glomerular basement membrane thickening with splitting of Bowman's capsule, but no mesangial alteration. Treatment with metformin effectively prevented the mesangial and glomerular basement membrane alterations (kidney) and maintained the normal architecture and visible distribution of the cardiac muscle fibers and nuclei.

Various rodent studies have shown that long-term feeding with HFD or HSD essentially led to dyslipidemia [43-46]. Consistent with past animal studies, we observed a significant increase $(p<0.005)$ in the plasma levels of triglycerides, total cholesterol, HDL-cholesterol and LDL-cholesterol in the HFD and HFD+HSD groups. The HSD group showed significant increase in triglycerides, total cholesterol, LDL-cholesterol and decrease in HDL cholesterol. Obesity and diabetes are commonly associated dyslipidemia [47]. Diets high in fat, especially saturated fat, are known to elevate plasma levels of triglycerides, total cholesterol and LDL-cholesterol [48].
Consumption of diets high in sucrose is also known to induce dyslipidemia. Sucrose, upon ingestion, is broken down into glucose and fructose by enzyme sucrase in intestine. Unlike glucose, fructose which bypasses two major steps (glucokinase and phosphofructokinase) in glycolysis and preferentially enter lipogenesis pathway [43]. As a result, large proportion of carbon deriving from the fructose fraction of the sucrose is converted into fatty acids in the liver and the rate of lipid synthesis in the liver is accelerated. This consequently leads to increase in the plasma lipid and cholesterol levels [43-45]. It is well documented that diet high in fat ironically increases the level of HDL, which is known as the good cholesterol. As can be seen in Figure 6, HDL levels in mice fed with HFD and a combination of HFD and HSD were significantly greater in comparison to mice fed mice fed normal diet (NC). It is well documented that consuming diet high in saturated fat and cholesterol ironically elevates the level of HDL, the good cholesterol [49]. It is thought that the paradoxical increase in the level of HDL seen with high dietary fat intake is a way of our body to counter the increased atherogenic risk associated with high saturated fat intake [50]. The latter demonstrated that consumption of diet high in saturated fat and cholesterol elevates HDL-cholesterol levels by decreasing the catabolic rates of HDL via decreasing HDL cholesterol ester and apolipoprotein A-I. Thus it is normal to observe an increase in the HDL level with high dietary fat intake. As for mice fed HSD, HDL-cholesterol level, in a contrary to other groups, were lower than mice fed with normal diet at the end of the experimental period. Typically, type 2 diabetes is often accompanied by low HDL levels and elevated plasma triglycerides and LDL-cholesterol levels [51]. The precise mechanism underlying the cause of low HDL-cholesterol level in type 2 diabetes is still unclear but it is thought that the increase in the activities of cholesteryl ester transfer protein and endothelial lipase in the state of hypertriglyceridemia accelerates the rate of HDL catabolism [52]. Thus the low level of HDL we observed in mice fed with HSD is consistent with findings from various previous studies.

Nevertheless, treatment with metformin for $10 \mathrm{w}$ while consuming HFD, HSD or HFD+HSD demonstrated significant prevention of increased levels of Total cholesterol, Triglycerides, HDL-cholesterol and LDL-cholesterol in comparison to the respective non-treated groups (Figure 7). Various rodent and human studies have also documented the beneficial effects of metformin on blood lipid profile [48,53-56]. Geerling et al. [57] observed reduction in plasma Total cholesterol (36\% lower compared to control) and triglyceride (38\% lower compared to control) levels after $4 \mathrm{w}$ metformin treatment in the mice fed cholesterol rich diet. Similarly, Kim et al. [48] have shown that metformin treatment significantly lowered TC, TG and LDL-cholesterol plasma levels in obese mice. Consistent with past findings, our study design demonstrated the ability of metformin to significantly improve lipid profiles of the mice with diet-induced obesity and diabetes. Overall, our results evidently showed metformin is effective in alleviating dyslipidemia which co-existed in obesity and diabetes. Metformin improves lipid profile by 
inhibiting the hepatic synthesis of cholesterol and triglycerides via activation of AMP-activated protein kinase (AMPK) in the liver [58].

Reactive oxygen species production has been commonly documented to play a crucial role in the pathogenesis of type- 2 diabetes [59] and diabetic nephropathy [59-61]. Our previous study evidently demonstrated the concordance of increasing ROS levels in peripheral blood as HbA1c (Glycated hemoglobin) levels in peripheral blood increased. ROS levels also demonstrated a positive correlation with ACR (Albumin to Creatinine Ratio) in urine samples [62]. HbA1c [63] and ACR [64] are the current gold standard markers for diagnosis and management of diabetes (both types 1 and 2) and nephropathy respectively. Nonetheless, various studies have also documented that high fat and high sucrose diets increased mitochondrial ROS $[65,66]$, therefore, contributes inevitably to the pathogenesis of obesity and diabetes. In the current study we quantitated ROS and in-situ ROS defense system in plasma of mice fed with high fat diet (HFD) and normal diet (Control) at d 0 (before consuming HFD) and after $182 \mathrm{~d}$ of HFD consumption. We observed that ROS levels in group of mice fed with HFD was maintained at normal physiological limits (normal limit: $<2.36 \mathrm{mmol} / \mathrm{L}$ ) $[67,68]$ with reference to the control group (Figure 5A). In-situ ROS defense system level in the control group demonstrated slightly higher level $(\mathrm{p}>0.05)$ after consumption of normal diet for $30 \mathrm{~d}$ (Figure $5 \mathrm{~B}$ ). The latter slight increase in in-situ ROS defense system level could probably be due to restrained stress instead of diet induced oxidative stress. HFD group on the other hand demonstrated significant increase in ROS defense level after $182 \mathrm{~d}$ of consuming HFD. The latter finding suggests that ROS was significantly generated from the metabolism of HFD and the in-situ antioxidant defense system had efficiently functioned to neutralize the increased ROS to homeostasis level (Figure 5A). Subsequently, the significant $(\mathrm{p}<0.05)$ increase in in-situ antioxidant system (normal limits: 1.07-1.53 Trolox units) $[67,68]$ in HFD group confirms that the in-situ antioxidant system was up regulated due to the presence of high ROS levels produced during HFD metabolism (Figure 5B).

\section{Conclusions}

$45 \% \mathrm{kcal}$ fat along with other essential proportion of nutrients and $40 \%$ sucrose solution effectively induced obesity in mice. The outcomes of this study cohesively demonstrated oral metformin therapy was effective in lowering body weight and blood glucose at the same time in a mouse model. $10 \mathrm{~d}$ oral metformin therapy led to significant weight reduction, glycemic control as well as improved lipid profiles in experimental diet-induced obesity and diabetes. Since metformin is commonly used in as a pharmacological intervention to manage hyperglycemia in patients, the findings of this study suggests that metformin will be an effective intervention for weight lost in obese or overweight type II diabetic patients as well as addressing the co-existing obesity and type 2 diabetes related dyslipidemia. Further large scale translational studies in human will be beneficial in confirming the pleiotropic effects of metformin as a cost effective intervention for obesity and type 2 diabetes along with coexisting cardio-metabolic risk factors.

\section{Funding}

This study was funded by Early Career Research Grant 2014 (ECR2014).

\section{Authors' CONTRIBUTIONS}

1. Christina GY-Contributed in organization of the experimental design, conducting experimental laboratory works, preparation of Figures and Table, initiation, organization and drafting of this manuscript.

2. Narendra Pamidi-Contributed in organization of the experimental design, conducting experimental laboratory works and drafting the histology discussion.

3. Rakesh Naidu-Contributed in the organization of the experimental design, organizations of manuscript, Figures and Table.

4. Kim Dae Jin-Contributed in conducting experimental laboratory works, data collection, data management, statistical analysis and tabulation of results.

5. Srinivasa Rao Sirasanagandla-Contributed in statistics and results analysis.

\section{Acknowledgements}

We would like to thank Jeffery Cheah school of Medicine and Health Sciences, Monash University Malaysia and the Early Career Research Committee (ECR) for funding this project.

\section{References}

1. Ki NK, Lee HK, Cho JH, Kim SC, Kim NS. Factors affecting metabolic syndrome by lifestyle. J Phys Ther Sci 2016; 28: 38-45.

2. Majid E. Trends in adult body-mass index in 200 countries from 1975 to 2014: a pooled analysis of 1698 population-based measurement studies with 19.2 million participants. Lancet 2016; 387: 1377-1396.

3. Ng M, Fleming T, Robinson M, Thomson B, Graetz N, Margono C, Gakidou E. Global, regional, and national prevalence of overweight and obesity in children and adults during 1980-2013: a systematic analysis for the Global Burden of Disease Study. Lancet 2014; 384: 766-781.

4. Cerf ME. Beta cell dysfunction and insulin resistance. Front Endocrinol (Lausanne) 2013; 4: 37.

5. Bennett WL, Odelola OA, Wilson LM, Bolen S, Selvaraj S, Robinson KA, Bass EB, Puhan MA. Evaluation of guideline recommendations on oral medications for type 2 diabetes mellitus: a systematic review. Ann Intern Med 2012; 156: 27-36. 
6. Ong CR, Molyneaux LM, Constantino MI, Twigg SM, Yue DK. Long-term efficacy of metformin therapy in nonobese individuals with type 2 diabetes. Diabetes Care 2006; 29: 2361-2364.

7. Sterne J. Pharmacology and mode of action of hypoglycaemic guanidine derivatives. In: Campbell GD, editors. Oral hypoglycaemic agents. London Academic $1969 ; 193-245$.

8. Seifarth C, Schehler B, Schneider HJ. Effectiveness of metformin on weight loss in non-diabetic individuals with obesity. Exp Clin Endocrinol Diabetes 2013; 121: 27-31.

9. Golay A. Metformin and body weight. Int J Obes (Lond) 2008; 32: 61-72.

10. Woods SC, Seeley RJ, Rushing PA, DAlessio D, Tso P. A controlled high-fat diet induces an obese syndrome in rats. J Nutr 2003; 133: 1081-1087.

11. Hariri N, Thibault L. High-fat diet-induced obesity in animal models. Nutr Res Rev 2010; 23: 270-299.

12. Al-Goblan AS, Al-Alfi MA, Khan MZ. Mechanism linking diabetes mellitus and obesity. Diab Metabol Syndr Obes Targets Ther 2014; 7: 587-591.

13. Wang CY, Liao JK. A mouse model of diet-induced obesity and insulin resistance. Methods Mol Biol 2012; 821: 421-433.

14. Qian C, Zhu C, Yu W, Jiang X, Zhang F. High-fat diet streptozotocin-induced type 2 diabetes in rats impacts osteogenesis and Wnt signaling in bone marrow stromal cells. PLoS One 2015.

15. He L, Meng S, Germain-Lee EL, Radovick S, Wondisford FE. Potential biomarker of metformin action. J Endocrinol 2014; 221: 363-369.

16. Kiernan JA. Histological and histochemical methods: theory and practice (5th Edn.). Banbury, UK: Scion 2015.

17. Cardiff RD, Miller CH, Munn RJ. Manual hematoxylin and eosin staining of mouse tissue sections. Cold Spring Harb Protoc 2014; 2014: 655-658.

18. Fakfruddin S, Alanazi W, Jackson KE. Diabetes-induced reactive oxygen species: mechanism of their generation and role in renal injury. J Diab Res 2017.

19. Tsang MW. The management of type 2 diabetic patients with hypoglycaemic agents. ISRN Endocrinol 2012; 2012: 478120.

20. Nasri H, Rafieian-Kopaei M. Metformin: current knowledge. J Res Med Sci 2014; 19: 658-664.

21. De Fronzo RA, Goodman AM. Efficacy of metformin in patients with non-insulindependent diabetes mellitus. The Multicenter Metformin Study Group. N Engl J Med 1995; 333: 541-549.

22. Seifarth C, Schehler B, Schneider HJ. Effectiveness of metformin on weight loss in non-diabetic individuals with obesity. Exp Clin Endocrinol Diabetes 2013; 121: 27-31.

23. De Jager J, Kooy A, Lehert P, Wulffele MG, van der Kolk, J, Bets D, Stehouwer CD. Long term treatment with metformin in patients with type 2 diabetes and risk of vitamin B-12 deficiency: randomized placebo controlled trial. BMJ 2010.
24. Schmidt MI, Duncan BB. Diabesity: an inflammatory metabolic condition. Clin Chem Lab Med 2003; 41: 1120-1130.

25. Meneghini LF, Orozco-Beltran D, Khunti K, Caputo S, Damçi T, Liebl A, Ross SA. Weight beneficial treatments for type 2 diabetes. J Clin Endocrinol Metab 2011; 96: 3337-3353.

26. Ponziani FR, Pecere S, Gasbarrini A, Ojetti V. Physiology and pathophysiology of liver lipid metabolism. Expert Rev Gastroenterol Hepatol 2015; 9: 1055-1067.

27. Aller EE, Abete I, Astrup A, Martinez JA, van Baak MA. Starches, sugars and obesity. Nutrients 2011; 3: 341-369.

28. Tillman EJ, Morgan DA, Rahmouni K, Swoap SJ. Three months of high-fructose feeding fails to induce excessive weight gain or leptin resistance in mice. PLoS One 2014; 9: 107206.

29. Hermann LS, Karlsson JE, Sjostrand A. Prospective comparative study inNIDDM patients of metformin and glibenclamide with special reference to lipid profiles. Eur J Clin Pharmacol 1991; 41: 263-265.

30. Desilets AR, Dhakal-Karki S, Dunican KC. Role of metformin for weight management in patients without type 2 diabetes. Ann Pharmacother 2008; 42: 817-826.

31. Drucker DJ. Gut adaptation and the glucagon-like peptides. Gut 2002; 50: 428-435.

32. Matsui Y, Hirasawa Y, Sugiura T, Toyoshi T, Kyuki K, Ito M. Metformin reduces body weight gain and improves glucose intolerance in high-fat diet-fed C57BL/6J mice. Biol Pharm Bull 2010; 33: 963-970.

33. Sumiyoshi M, Sakanaka M, Kimura Y. Chronic intake of high-fat and high-sucrose diets differentially affects glucose intolerance in mice. J Nutr 2006; 136: 582-587.

34. Ahren B, Scheurink AJ. Marked hyperleptinemia after high-fat diet associated with severe glucose intolerance in mice. Eur J Endocrinol 1998; 139: 461-467.

35. Brenner RR, Rimoldi OJ, Lombardo YB, Gonzalez MS, Bernasconi AM, Chicco A, Basabe JC. Desaturase activities in rat model of insulin resistance induced by a sucrose-rich diet. Lipids 2003; 38: 733-742.

36. Muurling $\mathrm{M}$, Jong $\mathrm{MC}$, Mensink RP, Hornstra G, Dahlmans VE, Pijl H, Voshol PJ, Havekes LM. A low-fat diet has a higher potential than energy restriction to improve high-fat diet-induced insulin resistance in mice. Metabolism 2002; 51: 695-701.

37. Pagliassotti MJ, Prach PA, Koppenhafer TA, Pan DA. Changes in insulin action, triglycerides, and lipid composition during sucrose feeding in rats. Am J Physiol 1996; 271: 1319-1326.

38. Luyckx AS, Lefebvre PJ. Plasma insulin in reactive hypoglycemia. Diabetes 1971; 20: 435-442.

39. Schultes B, Oltmanns KM, Kern W, Fehm HL, Born J, Peters A. Modulation of hunger by plasma glucose and metformin. J Clin Endocrinol Metab 2003; 88: 1133-1141.

40. Giannarelli R, Aragona M, Coppelli A, Del Prato S. Reducing insulin resistance with metformin: the evidence today. Diabetes Metab 2003; 29: 28-35. 
41. Hundal RS, Inzucchi SE. Metformin: new understandings, new uses. Drugs 2003; 63: 1879-1894.

42. Shaker SM, Magdy YM, Abd-Elaziz LF, El-Said SA, Alkharashy OA, Nabeeh ES. Histological study on the effect of metformin on high-fat-diet-induced liver injury in adult male albino rats. Egypt $\mathrm{J}$ Histol 2014; 37: 592-602.

43. Cao $\mathrm{D}, \mathrm{Lu} \mathrm{H}$, Lewis $\mathrm{TL}, \mathrm{Li}$ L. Intake of sucrosesweetened water induces insulin resistance and exacerbates memory deficits and amyloidosis in a transgenic mouse model of Alzheimer disease. J Biol Chem 2007; 282: 36275-36282.

44. Stanhope KL, Schwarz JM, Keim NL, Griffen SC, Bremer AA, Graham JL, Havel PJ. Consuming fructosesweetened, not glucose-sweetened, beverages increases visceral adiposity and lipids and decreases insulin sensitivity in overweight/obese humans. J Clin Invest 2009; 119: 1322-1334.

45. Hirahatake KM, Meissen JK, Fiehn O, Adams SH. Comparative effects of fructose and glucose on lipogenic gene expression and intermediary metabolism in HepG2 liver cells. PLoS One 2011; 6: e26583.

46. Sumiyoshi M, Sakanaka M, Kimura Y. Chronic intake of high-fat and high-sucrose diets differentially affects glucose intolerance in mice. J Nutr 2006; 136: 582-587.

47. Despres JP, Moorjani S, Tremblay A, Ferland M, Lupien PJ, Nadeau A, Bouchard C. Relation of high plasma triglyceride levels associated with obesity and regional adipose tissue distribution to plasma lipoprotein-lipid composition in premenopausal women. Clin Invest Med 1989; 12: 374-380.

48. Kim EK, Lee SH, Jhun JY, Byun JK, Jeong JH, Lee SY, Kim JK, Choi JY, Cho ML. Metformin prevents fatty liver and improves balance of white/brown adipose in an obesity mouse model by inducing FGF21. Mediators Inflamm 2016.

49. Schaefer EJ, Levy RI, Ernst ND, Van Sant FD, Brewer HBJr. The effects of low cholesterol, high polyunsaturated fat, and low fat diets on plasma lipid and lipoprotein cholesterol levels in normal and hypercholesterolemic subjects. Am J Clin Nutr 1981; 34: 1758-1763.

50. Hayek T, Ito YA, Verdery RB, Aalto SK, Walsh AB JL. Dietary fat increases high density lipoprotein (HDL) levels both by increasing the transport rates and decreasing the fractional catabolic rates of HDL cholesterol ester and apolipoprotein (Apo) A-I. Presentation of a new animal model and mechanistic studies in human Apo A-I transgenic and control mice. J Clin Invest 1993; 91: 1665-1671.

51. Barter PJ. The causes and consequences of low levels of high density lipoproteins in patients with diabetes. Diab Metabol J 2011; 35: 101-106.

52. Barter PJ. Hugh sinclair lecture: the regulation and remodelling of HDL by plasma factors. Atheroscler Suppl 2002; 3: 39-47.
53. DeFronzo RA, Goodman AM. Efficacy of metformin in patients with non-insulin dependent diabetes mellitus. The Multicenter Metformin Study Group. N Engl J Med 1995; 333: 541-549.

54. Salpeter SR, Buckley NS, Kahn JA, Salpeter EE. Metaanalysis: metformin treatment in persons at risk for diabetes mellitus. Am J Med 2008; 121: 149-157.

55. Forouzandeh F, Salazar G, Patrushev N, Xiong S, Hilenski L, Fei B, Alexander RW. Metformin beyond diabetes: pleiotropic benefits of metformin in attenuation of atherosclerosis. J Am Heart Assoc 2014; 3: 001202.

56. de Lima LMA, WiernspergerN, Kraemer-Aguiar LG, BouskelaE. Short-term treatment with metformin improves the cardiovascular risk profile in first-degree relatives of subjects with type 2 diabetes mellitus who have a metabolic syndrome and normal glucose tolerance without changes in C-reactive protein or fibrinogen. Clinics (Sao Paulo, Brazil) 2009; 64: 415-420.

57. Geerling JJ, Boon MR, van der Zon GC, van den Berg SA, van den Hoek AM, Lombes M, GuigasB. Metformin lowers plasma triglycerides by promoting VLDLtriglyceride clearance by brown adipose tissue in mice. Diabetes 2014; 63: 880-891.

58. Foretz M, Viollet B. Regulation of hepatic metabolism by AMPK. J Hepatol 2011; 54: 827-829.

59. Nishikawa T, Araki E. Impact of mitochondrial ROS production in the pathogenesis of diabetes mellitus and its complications. Antioxidants Redox Signal 2007; 9: 343-353.

60. Dronavalli S, Duka I, Bakris GL. The pathogenesis of diabetic nephropathy. Nat Clin Pract Endocrinol Metabol 2008; 4: 444-452.

61. Kanwar YS, Sun L, Xie P, Liu F. A glimpse of various pathogenetic mechanisms of diabetic nephropathy. Ann Rev Pathol Mech Dis 2011; 6: 395-423.

62. Yap CG, Zaini A, Othman I. Targeted CYP2E1 quantification and its correlation to currently acceptable clinical biochemical indices. J Biol Res Thessaloniki 2016; 23: 5 .

63. Saudek CD, Herman WH, Sacks DB, Bergenstal RM, Edelman D, Davidson MB. A new look at screening and diagnosing diabetes mellitus. J Clin Endocrinol Metab 2008; 93: 2447-2453.

64. Kowalski A, Krikorian A, Lerma EV. Diabetic nephropathy for the primary care provider: new understandings on early detection and treatment. Ochsner J 2014; 14: 369-379.

65. Sverdlov AL, Elezaby A, Behring JB, Bachschmid MM, Luptak I, Tu VH, Siwik DA, Miller EJ, Liesa M, Shirihai OS, Pimentel DR, Cohen RA, Colucci WS. High fat, high sucrose diet causes cardiac mitochondrial dysfunction due in part to oxidative post-translational modification of mitochondrial complex II. Journal of Molecular and Cellular Cardiology. 2015; 78: 165-173.

66. Qin Z, Hou X, Weisbrod RM, Seta F, Cohen RA, Tong X. Nox2 mediates high fat high sucrose diet-induced nitric 
Pleiotropic effects of metformin in managing type 2 diabetes and metabolic syndrome: evidences from experimental mouse model

oxide dysfunction and inflammation in aortic smooth muscle cells. J Mol Cell Cardiol 2014; 72: 56-63.

67. Palmieri B, Sblendorio V. Oxidative stress tests: overview on reliability and use. Part I. Eur Rev Med Pharmacol Sci 2007; 11: 309-342.

68. Palmieri B, Sblendorio V. Oxidative stress tests: overview on reliability and use. Part II. Eur Rev Med Pharmacol Sci 2007; 11: 383-439.

\section{*Correspondence to}

Christina Gertrude Yap

Jeffrey Cheah School of Medicine and Health Sciences

Monash University Malaysia

Malaysia 